\title{
Research on the Construction of Energy Network Based on Modular Energy Service Industry
}

\author{
Dong Jun, Lv Shanlei, Wang Dongxue, Guo Yuanzheng \\ Department of Economics and Management, North China Electric Power University, Beijing, China \\ Email address: \\ 1195188299@qq.com (Lv Shanlei), 1175552490@qq.com (Wang Dongxue)
}

To cite this article:

Dong Jun, Lv Shanlei, Wang Dongxue, Guo Yuanzheng. Research on the Construction of Energy Network Based on Modular Energy Service Industry. American Journal of Energy Engineering. Vol. 5, No. 5, 2017, pp. 26-33. doi: 10.11648/j.ajee.20170505.11

Received: September 14, 2017; Accepted: September 29, 2017; Published: November 8, 2017

\begin{abstract}
The energy services industry in China is still in the early stage of development, and it's the size of the industry as well as the existing service level is not enough to meet the diverse needs of the market, and the current industry value chain system is not perfect enough. This paper first analyzes the main elements of the energy service industry and its main body behavior, and further sums up the value link between the various subjects; Secondly, based on the modular and value network theory, the construction of energy service industry value network, the main purpose is to increase the understanding of the energy service industry value network and operational mechanism. The results show that the energy service industry value network is different from the traditional value network system. Under the impetus of the modularization trend, the multi-service module main body, the division of labor and cooperation among the major modules, effectively integrated into the industrial value network to achieve value creation and maximize value.
\end{abstract}

Keywords: Energy Services Industry, Modularization Value Network, Operating Mechanism

\section{Introduction}

In the past ten years, China's energy services industry has experienced a process from no, little to large, especially since the reform of electricity, China's energy service industry has been developing in a positive way, which has been characterized by rapid expansion of the industry scale, intensifying industrial competition and the gradual expansion of the energy service market. The energy service industry is a new industry and a complex network system, which involves multiple subjects, multi-products, multi-technology and multi-value. Energy service industry is mainly involved in the main energy services companies, energy companies, financial institutions, equipment suppliers, design units, construction units, third-party certification bodies and government regulatory authorities, the energy services industry's business scope includes not only energy consulting services and energy-saving technical services, its subjects are interrelated, which provides a variety of energy efficiency products and services in a variety of energy-saving technologies, financing instruments and business models.

Nowadays, enterprises have entered the era of "modularization", and the synergization and clustering of industrial development has gradually changed the traditional value network organization form. Canes M E, France N discusses the special economic issues under federal energy management through the application of linear programming techniques [1]. Zhu Xuefei on the energy service company financial management system for a comprehensive analysis, which was from the value chain point of view, on this basis, the energy service service value model was put forward, and the value chain framework of energy saving service enterprise was constructed [2]. Michael Hammer believes that in the value of the network, the company is no longer a complete enterprise, but only their own competitive advantage of the core business areas, as a business model, it combines high quality resources and competencies of members in an intangible network platform to create new sources of value [3]. Geoff Burrows, Christopher Black conducted exploratory research on the benefit sharing of six Australian accounting firms, introducing three methods of benefit sharing: average sharing, performance sharing and averaging and performance [4]. On the basis of creating shared value theory, Liu $\mathrm{Na}$ analyzes the cooperative relationship between the main body of energy service companies [5]. Zhang Chaobin analyzes the relationship between the modules in the modular value 
network, and sums up the following points: cooperation is to improve the core competitiveness, competition is for better cooperation, value creation and distribution mechanism can effectively promote the mechanism network The stable operation [6]. Chen Jian constructed the value network of energy services industry by using the theory of value network, and studied the value creation mechanism and value distribution strategy of value net in depth. [7]. Under the contract energy management mode, Huang Zhixing studied the investment decision-making of the energy-saving benefit-sharing project, and summed up the significance of the energy management mode under the energy-saving benefit sharing [8]. Zhang Xiangyang and Yang Mincai analyzed the principles of risk in supply chain and risk sharing, and studied the risk sharing and benefit distribution mechanism in supply chain [9]. Duan Xiaoping made a deep analysis of the causes of the financing risks of China's energy-saving service industry, and put forward countermeasures and suggestions on the financing risks and operating mechanism of China's energy-saving service industries from several aspects [10].

\section{The Model of the Energy Service Industry System}

\subsection{The Main Part and Behavior Characteristics of the Energy Service Industry}

China's energy service industry is in response to the call of the national policy of the rise of energy-saving services, the industry's energy-saving service system has been initially established. Among the many constituent elements, the main part of the energy service industry includes three parties: energy consumption enterprises, energy service enterprises and equipment suppliers. Energy-saving services companies can provide the following services for energy companies: consulting, financing, equipment transformation and energy efficiency goals; According to the energy-saving service enterprises to develop energy-saving plan, the supply of equipment can give energy-consuming enterprises to provide low-power equipment.

In the energy service industry system, energy consumption enterprises play the main role, in the production and operation of the enterprise operating costs are accompanied by a certain resource and energy loss.. Therefore, energy consumption enterprises focus on energy efficiency issues. In the macro background of the state encouraging the development of energy conservation industry, China's energy-consuming enterprises have become the main customers of energy saving services.

Energy-saving service enterprises are the makers of the target of the whole industry system, mainly in the form of contract energy management to implement energy-saving diagnosis, design and transformation, financing and operation and management of energy-saving services, the corresponding agreed energy savings are achieved by improving the energy efficiency of energy companies.

Energy-saving equipment suppliers are energy-consuming enterprises to provide customers with low-power equipment, energy-saving service enterprises and energy companies signed a contract, equipment suppliers to test the energy consumption of enterprise equipment and determine its detailed data, design equipment replacement program to help energy-saving service enterprises for energy companies to develop a more comprehensive energy-saving program.

As a party that provides financial support to the energy service project, the financing party has an important position in the industrial system, mainly the energy conservation service fund, the bank, the guarantee company, the venture company, venture Capital has signed an insurance contract for energy-saving service enterprises, venture capital companies to inject funds, energy-saving services company for venture capital firms to provide risk income. The Energy Conservation Services Foundation provides financial support for energy efficiency services and ensures the accuracy of the project.

\subsection{The Relation of the Principal Value of the Energy Service Industry}

Under the guidance of customer centrality management trend, energy consumption enterprise is the potential demand part of energy conservation service enterprises, and the dynamic relationship between the main part and the form of contract is formed.

a. Energy - saving service enterprises - energy consumption enterprises - equipment suppliers

The value link of energy saving service enterprise and energy consumption enterprise

The primary issue of this value relationship is service orientation and service proposition, which is to identify the target customer and the customer's needs to clarify the purpose of the service. Energy consuming enterprises often occupy a dominant position in the service system, which requires the energy conservation service enterprises to follow the principle of demand, set goals from their fundamental needs and interests, in this way, we can obtain more economic profit from the revenue of energy consuming enterprises in terms of contract management. Service orientation and service proposition are finally reflected in the service goals, and the energy saving service enterprises make service plans according to the diversification of target customers.

The value link of energy saving service enterprises and equipment suppliers

Energy saving service enterprises to choose the strategic goals and corporate culture with the same equipment suppliers, prevent the occurrence of adverse selection behaviors, and the energy consumption of enterprise comprehensive assessment of the following indicators: operating efficiency, technology level, set up index system of energy efficiency. Select equipment suppliers to establish strategic partnership, provide bargaining power, and reduce costs as much as possible to increase revenue sharing.

The value link of energy consuming enterprises and equipment suppliers

In order to meet the requirements of energy consuming enterprises, energy saving enterprises attract energy 
consumers to the supply process of equipment suppliers, and use equipment transformation and replacement to carry out the service. At the same time, stimulated the willingness of the equipment suppliers to join and promote the increase in the interests of the group, and ultimately achieve greater value flow.

b. Energy saving service enterprises -- energy consuming enterprises -- other stakeholders

The value link of energy-saving service enterprises and other stakeholders

Other stakeholders can be divided into two types: a non-market access model, which includes governments that subsidize and acquire taxes, competitors who compete with companies and complements to provide complementary energy saving services. The other is market access, which includes investors and partners who derive benefits from their earnings. Energy-saving service enterprises should work with other stakeholders to create value and compete with stakeholders to gain value.

The value link of energy companies and other stakeholders

A certain intersection exists between the energy consumption enterprises and other stakeholders, the operating policies formulated by investors may affect the purchase of energy-saving services to energy-consuming enterprises, and energy demand for energy consumption enterprise customers will directly affect the value of the enterprise and the benefits of investors. At the same time, the recognition of energy consumption enterprises directly determines whether the enterprise can establish a good cooperative relationship with the complementary enterprises, and the energy consuming enterprises may also switch to purchasing alternative services, therefore, each industry part will consider the realization of the value of other industrial entities while pursuing its own profit maximization.

\section{Construction of Modular Value Network of Energy Service Industry}

\subsection{Value Network and Value Module}

The concept of value network is evolved from the value chain, which has a profound background of the times, the result of the internal and external environment faced by the enterprise, and the result of technological development. The development of network information technology objectively promoted the generation and development of value network, which makes the value network not only a concept, but also the possibility of concrete reality.

The value network reflects the characteristics of the market and the competitive environment, representing a new type of production organization that responds to changes through close cooperation, and it is far beyond the meaning of the concept of joint and the collaboration between enterprises in the past. Value network development is actually the process of creating value, an enterprise by reshaping enterprise internal and external relationship model, thus changed the way of enterprise resource allocation and the value of different value subject integration mode, increasingly complex network relations formed between the enterprises, enterprises pay more attention to the close cooperation and exchanges between the organization and its community, interdependence and common development, to fight against all sorts of challenges brought by the environmental change and get the resources needed.

Nowadays, economic globalization and the development of new economic times, the development of industry and enterprise presents the development trend of modularization and value chain network. With the development of modularity, modularization as a new form of organization gradually evolves into the industrial organization or internal system modular. Modularization enables organizations to leverage existing resource portfolios to achieve a diversity of services and a low-cost reunification. The value module is the genome that forms the value chain, and the value chain is the genome that consists of a set of value modules in accordance with certain rules. Value modularity is a complex process of decomposition and integration of complex systems, through the decomposition and integration of the system value module, the complex system is decomposed into several independent modules, and then the independent modules are combined according to a certain connection rule, and the relationship between the modules is contracted to form a more complex value chain system, eventually forming a modular value network. The modular value network organization model is a macro cross-type value organization, including two levels:

a. Value network of enterprises

The competency elements of an enterprise are divided into core competencies and general ability elements, while the size of the enterprise becomes larger, more complex market relationships will be introduced between the internal modules of the enterprise, and the internal value chain will be extended, integrated and networked, enterprises to a (some) core competency elements as the center, the enterprise combines the different value chain and value module in the enterprise to form the value network system within the enterprise.

b. The external value network between the enterprise and the enterprise

In order to improve the competitiveness of their own organizations, enterprises are required to realize the sharing of resources and information between enterprises and establish an interdependent cooperative relationship. In order to cope with the impact of economic globalization, different value chain enterprises have adopted the strategy of enterprise alliance, the business between the two connections, the interests of enterprises and the interaction between the formation of an intertwined value system, namely external value between enterprise and enterprise network.

\subsection{Industrial Value Network Builds on the Basis of Modularity}

Modular energy services industry value network is not a one-way chain form, industrial chain cross each other, forming a network structure, this network structure to the various elements of the ability to coordinate in the same 
intangible network platform, through the network between the different modules of innovation, cooperation and competition to meet the energy service customers differentiated energy-saving goals, so as to better adapt to the fierce of the competitive market. In order to improve enterprise competitive advantage, companies tend to integrate into the different value chain between enterprises of the value of the network, through continuous optimization and eventually evolved into includes energy equipment suppliers, channel partners, skills, service providers, and competitors' value net energy services industry.

The value network is a macroscopic concept, the total is one, the change is infinite. The energy service industry value network is influenced by the above elements, cooperation and the evolution of the network. The realization of customer value is not accomplished by energy service enterprises alone, but it is the result of cooperation with energy consuming enterprise customers, equipment suppliers, technology service providers and government. For the energy service industry, the energy service industry value network is composed of energy saving service enterprises, equipment suppliers and energy consuming enterprises. Energy conservation service enterprises shall provide energy saving services for energy consuming enterprises, carry out technological renovation of energy-saving technologies, and improve the energy efficiency of enterprises. As the intermediate subject of energy saving service enterprises and energy consuming enterprises, equipment suppliers provide technical support for energy efficient service enterprises and provide equipment support for energy consuming enterprises. Other elements, such as energy efficiency management platform, government agencies, the financiers as an important part of the energy services industry value network, support network for the activities of the three parties together, as a result, the energy services industry value network structure shown in figure 1:

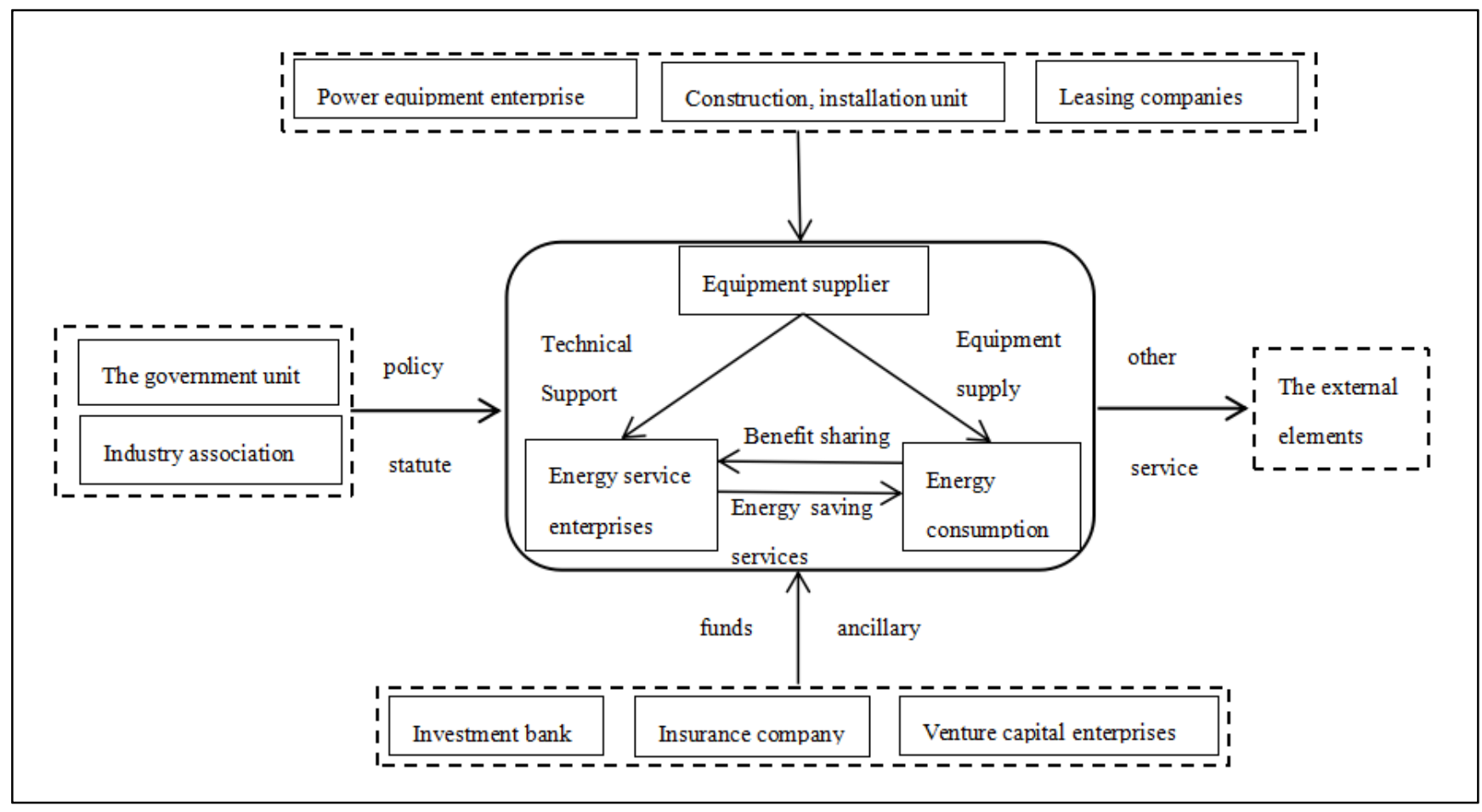

Figure 1. The energy services industry value network structure.

Value network is a kind of value creation system based on customer, and it is also a demand-pull system. The demand of energy-consuming enterprise is not only the starting point of the value network operation of energy service industry, but also the endpoint of value network operation. As a central enterprise within the value network, one of the key roles of energy service industry is to quickly and accurately identify the potential customer demand in the market, and to transmit the information to each participant in the value network in time, each participant can respond to the market condition and change quickly. The internal modules of value network are interconnected, and the value network structure is based on modularization, connecting the cooperating equipment suppliers together in order to develop and deliver the solution, and through the corresponding revenue sharing system, the benefit of the module is grouped together under the overall internal structure framework. The system characteristic of the value network structure of energy service industry is a kind of dynamic and continuous development, with the enlargement of the value network in the later period, the network will introduce more interest module and trading mechanism, which can adjust its structure with the change of customer's target demand of energy-consuming enterprise. At the same time, the value of the product or service is created by the various modules of the value network and integrated by the value network, each network members to create the value as part of the final value. 


\section{The Modular Operation Mechanism of Energy Service Value Network}

\subsection{Benefit-Sharing Mechanism of Energy Service Value Network}

A new kind of energy-saving mechanism based on marketization operation in the western developed countries in the the 1970s--contract energy management, energy-saving service enterprise is a kind of specialized company, which is based on the contract energy management mechanism operation, for the purpose of profit, they sign energy-saving service contract with energy-consuming enterprise customers, and provide energy-saving service for energy-consuming enterprises, including the efficiency analysis, the investment and financing of the project, and the procurement. Efficiency distribution mechanism of energy-saving project is based on

contract energy management, in the term of the contract of energy-saving project transformation, energy-consuming enterprises can improve energy utilization rate, energy saving and energy-saving efficiency by accepting energy-saving service, so that the energy consumption will be quantified under the existing technical conditions, and the funds spent by power-consuming enterprises to pay for energy-saving service cost, and to share energy-saving benefits in accordance with the proportion of the contract requirements, both sides to achieve energy efficiency. After the expiration of the contract of the energy-saving project, the energy-consuming enterprise as the service person continues to enjoy the future energy saving benefit. During the contract period, the cost of energy-consuming enterprise customers paid to energy-saving services company is all from the project-saving costs, as shown in Figure 2:

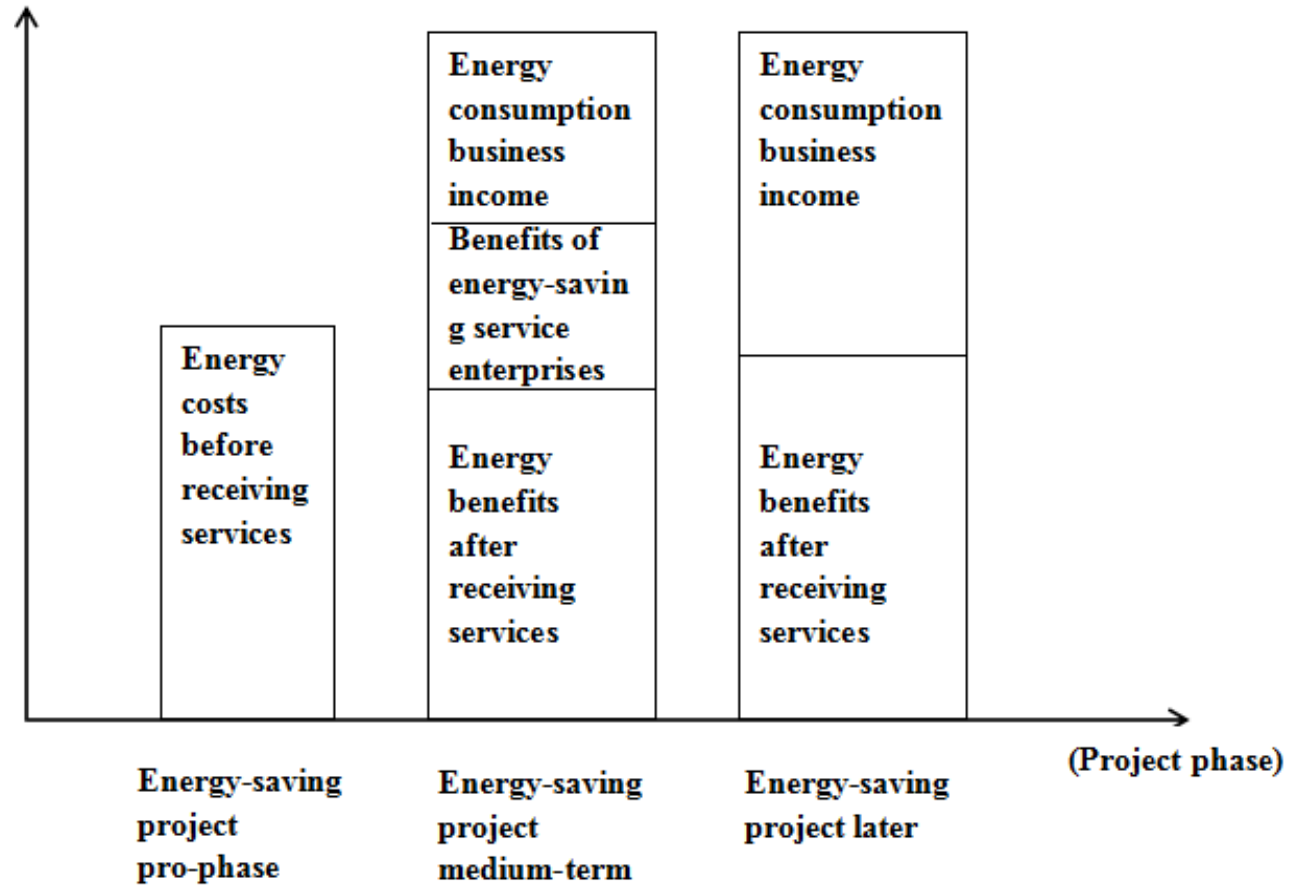

Figure 2. Energy efficiency sharing mechanism for energy service contracts.

During the development of energy-saving service project, the main principle of the benefit distribution of each module is to take the profit space of the participating projects as the first priority, and to demand the reasonable distribution of benefits, and the relationship between each interest subject is a value flow relationship based on contract and contract nature. After the entry into force of the contract, there is a legal mandatory service and the relationship between the services, the mutual economic relations between the period of the project to maintain relatively stable. In this value network system, the resources and contributions of the participating subjects in the energy-saving service projects become the decisive factors of their respective interests. Within the effective term of the contract energy management contract, energy service companies, equipment suppliers and consumer Energy enterprise customers in accordance with the proportional differentiation of energy efficiency, participation in the distribution of profits, mutual integration into a close dynamic alliance relationship, share the benefits, a total of risk.

\subsection{Power Mechanism of Energy Service Value Network}

The essence of the network operation of energy service value is that the network nodes focus on some or some service modules in the network, and the further deepening of the Division of Labor leads to increasing the degree of the increase of the income gradually. While concentrating on their core business, enterprises can get the demand of enterprises from the internal value network at lower price than outside, and the internal advantage, scale economy and division economy form a virtuous circle, and the power mechanism of energy service can be established. According to the characteristics and functions of power, the dynamical factors 
in the network power system of energy service value are divided into two categories: Network endogenous power and exogenous power. The exogenous power of network refers to the power generated by the internal network in the continuous development of the value network, and the external power is the power outside the network and can promote the network development.

a. Endogenous dynamical mechanism of energy service value Network

The endogenous dynamical mechanism of energy service value Network is also called the self-organization dynamic mechanism of energy service value network, and the key to form the self-organization dynamic mechanism of energy service value network lies in the industrial correlation, that is, in the development of the Energy Service network, the power of the network system to promote the internal module to coordinate development. With the further deepening of the Division of labor, the industrial correlation degree is increasing, the cooperation symbiosis between the energy service enterprises is formed, and the internal module of the network produces the demand of synergy and interdependence. Endogenous power is the decisive force in the Development of energy service network, which fundamentally plays a decisive role in the evolution and development direction of energy service network, and the network system composed of multiple modules makes the complex connection between modules through the following ways: energy-saving services, value flow, diffusion of knowledge and technology, multi-industry linkage. The role of each support system in the core theme system of energy-saving service enterprises, equipment suppliers and energy-consuming enterprises is the endogenous power source of energy service value network.

Core main body system function, the core main body system is by the energy-saving Service enterprise, the equipment supplier, the energy consumption Enterprise Constitution subsystem. Energy-saving project contract of energy-saving service enterprises and energy-consuming enterprises is the main source of network endogenous power. Energy-saving benefit sharing is an important driving force for energy-saving service enterprises to gain profits. Diversified energy-saving services stimulate energy-consuming enterprises to produce diversified energy-saving demand, therefore, from the perspective of demand, the energy Service value network, which takes the customers as the main body, has generated endogenous impetus. Support system function, support system is composed of government, energy-Saving Industry association, Bank, Power equipment enterprise and so on, and set up principal-agent relationship between the following core subjects: energy-saving Service enterprise, energy-consuming enterprise, equipment supplier, and finally, on the basis of fulfilling contract duty, produce endogenous power. Support systems provide technical, financial and policy support to advance the development of energy services projects and energy service value networks, the endogenous mechanism of energy service value network is shown in Figure 3:

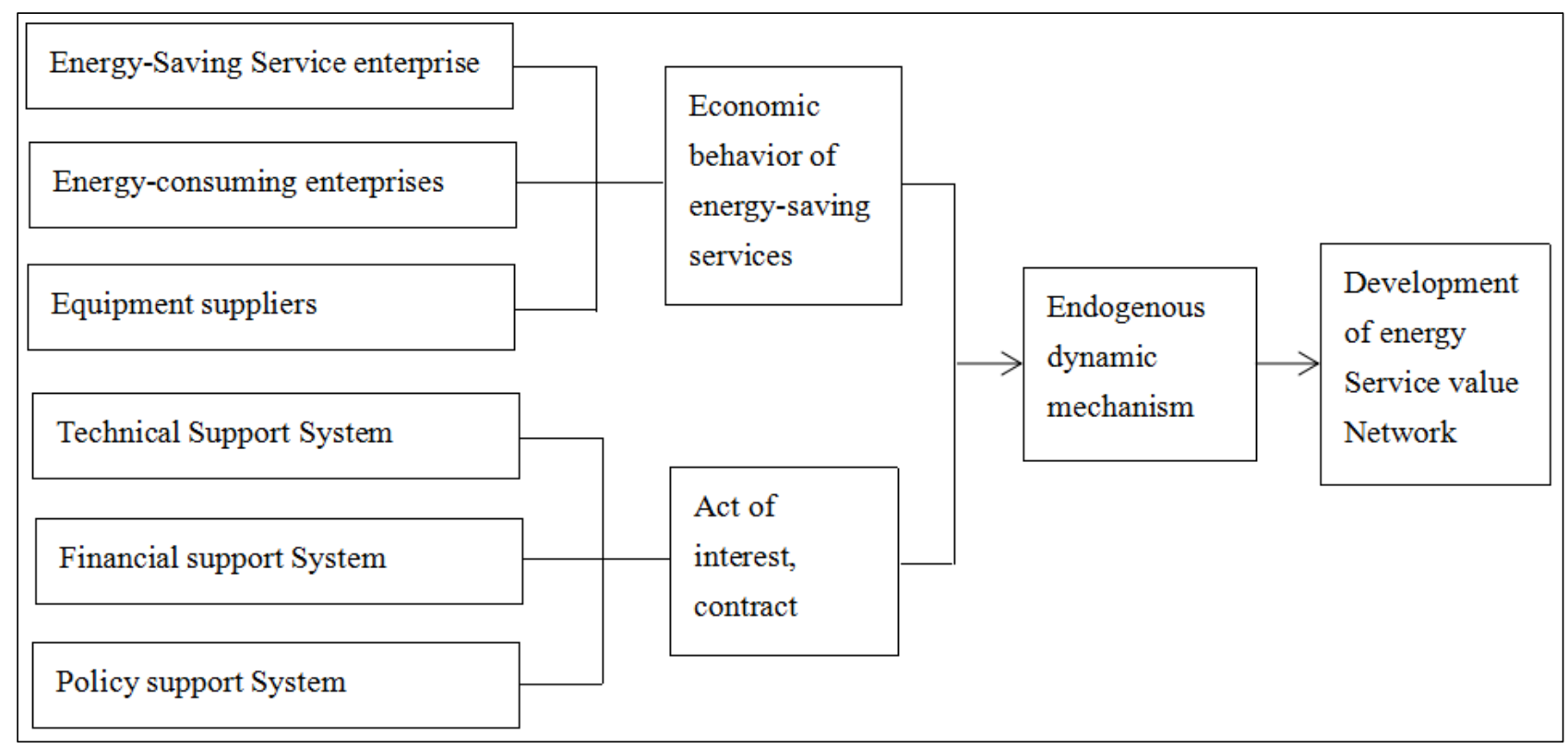

Figure 3. The endogenous mechanism of energy service value network.

b. Exogenous power mechanism of energy service value Network

The exogenous impetus mechanism of energy service value network is the external impetus force generated in the process of the development of energy service value network. Although the exogenous dynamical mechanism does not have the decisive influence on the development of the value network, the influence of the endogenous dynamical mechanism on the value network cannot be neglected. As an important part of the promotion of energy service system, national government departments and state grid companies are the main sources of exogenous power, which directly affect the operation of energy service system. As the macro-stakeholder of the development of energy service industry, the government 
department has the initiative to promote the development of energy service value network, which goes beyond the interest main body of local interests and affects the development of energy service system by enacting a series of policies and regulations, the exogenous mechanism of energy service value network is shown in Figure 4:

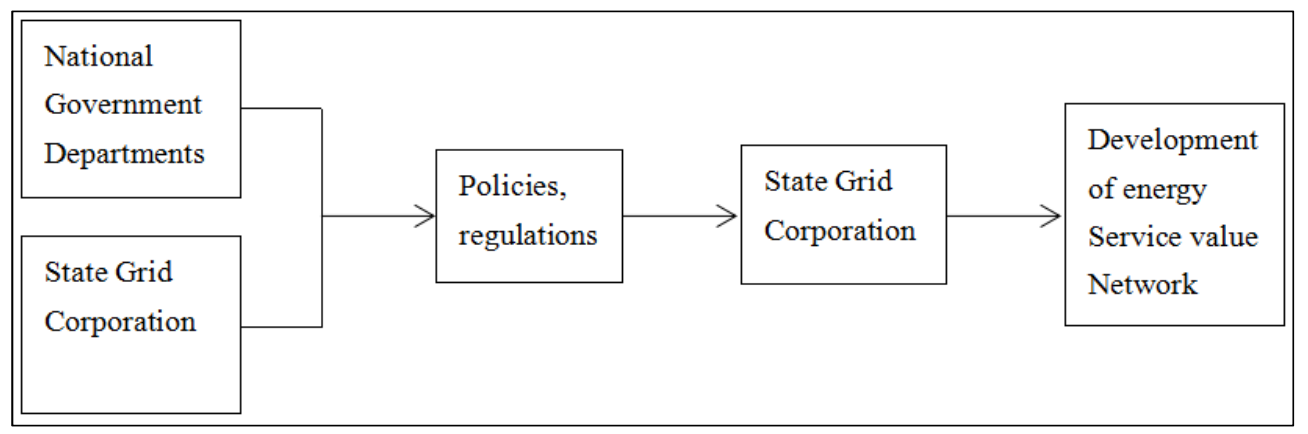

Figure 4. The exogenous mechanism of energy service value network.

\subsection{Value Generation Mechanism of Energy Service Value Network}

The value network has changed the relationship between the past and the single demand, and the overall coordination ability of the value network is that the system can respond more quickly to customer requirements. As the core subject of the system, energy service enterprises need to introduce the value modules which are closely related to the functions of energy service, to promote the docking of multi resources in the network system, to build a more powerful energy service industry, to form the function cluster of energy service industry, and to establish the scale advantage and reduce the cost of each node in the industrial chain, finally build a new value network. The purpose of energy service enterprises is to provide relevant energy-saving services, improve energy efficiency and gain profits. There are two ways to improve operating efficiency and income level in the process of energy service Enterprises ' operation and Development:

a. Based on the value generated within the enterprise. As the integrator of Value network, energy service enterprises should fully excavate the source of internal value creation of enterprises, enhance the efficiency of value creation in enterprises, and realize the value creation and creation of value. In the modular network organization, each service value module is to pursue the benefit maximization, and will choose the partner according to the market price, promotes the competition between the similar business entities, forms the cooperation between the different class but has the interrelated business entity. Enterprises need to clarify the value-creating activities and the correct division of labor, the collection of various types of enterprise capacity elements, the division of Value growth points, highlighting the core value-added business enterprises, enhance the value-creating capacity of enterprises to achieve economies of scale and scope of economic benefits.

b. Based on the enterprise boundary value generation. The industrial chain of energy services can be divided into several node enterprises, in addition to their own value-creating function, these nodes can also be coupled between enterprises, and the industry linkage, finally in the agreed interface to form a modular value network. With the enterprise's own value chain as the basis, the enterprise's core resources are extended to the outside enterprise, in order to seek the source of improving the value creation and service level from outside the enterprise. In a single enterprise with limited internal technology and funds, the network synergy between enterprises to create value, cooperation between the enterprises will be established across the border between the two sides of the cooperative relationship, within the value of the network within the transaction, to obtain a more favorable price, in the realization of the transaction cost reduction, while reduce the cost of network organization and can enhance the profitability of enterprises.

\section{Conclusion}

In the value network of energy service industry, value stream is a continuous value creation and value-added process, the value stream is no longer the simple flow on the industrial chain, but the active creation and absorption of each value module in the industrial value network, according to its own advantages, on the basis of specialization and characteristic, the main body of each module upgrades to the higher module or link in the modular value network, expands the coverage of the value network of energy service industry, optimizes the industrial structure, enhances the synergy between the network subjects, and finally realizes the value creation of the energy service industry value network.

In the Energy service industry Value Network, the energy-consuming enterprise customer becomes the core pulling power of the network development, which based on its diversified energy-saving service demand, and puts forward the new technical requirement unceasingly, the equipment supplier must continuously improve the existing technology and improve the equipment performance parameter. The supply and demand between energy-consuming enterprise and the energy service network node enterprise have stimulated the technological innovation, has promoted the energy service industry value network development. The development of the value network of energy service industry can help the energy service to get rid of the low end of the value chain, which is beneficial to the optimization and upgrading of China's energy 
service industry, so as to integrate the energy service industry into the global value network better and faster.

\section{References}

[1] Canes M E, France N. The peculiar economics of federal energy management [J]. Energy Policy, 2016, 91:268-272.

[2] Zhu Xuefei. Analysis on the financial management of value chain of energy-saving service company [D]. Shihezi University, 2016.

[3] Michael Hammer. Corporate Action Program [M]. Beijing: CITIC Publishing House. 2002.

[4] Burrows G, Black C. Profit sharing in Australian Big 6 accounting firms: An exploratory study is [J]. Accounting Organizations \& Society, 2004, 23(5-6):517-530.

[5] Liu Na. Based on the creation of shared value theory of EMC main cooperative relations research $[\mathrm{D}]$. Beijing Institute of Technology, 2016.

[6] Zhang Chaobin. Based on the modular value of China's animation industry network research [D]. Donghua University, 2013.

[7] Chen Jian. Based on the value chain theory of energy-saving service enterprise growth momentum mechanism [D]. Tianjin University, 2015.

[8] Huang Zhixing. Research on investment decision-making of energy-saving benefit-sharing project in contract management [D]. Beijing Jiaotong University, 2016.

[9] Zhangxiangyang, Yang, Liu Huaming, and so on. Research on risk sharing and benefit distribution mechanism in supply chain management $[\mathrm{J}]$. Journal of Huazhong University of Science and Hust (social Sciences Edition), 2004, 18 (5): 94-97.

[10] Duan Xiaoping. Study on the formation mechanism and Countermeasures of financing risk in energy-saving service industry [J]. accounting communication, 2017 (1). 